\title{
Anti-PD1/Anti-CTLA4 Antibody Mixture PSB205
}

National Cancer Institute

\section{Source}

National Cancer Institute. Anti-PD1/Anti-CT LA4 Antibody Mixture PSB205. NCI

Thesaurus. Code C162774.

A mixture of two eng ineered monoclonal antibodies produced by a single cell line of which one is directed against the human negative immunoregulatory checkpoint receptor programmed cell death protein 1 (PD-1; PDCD1; CD279) and the other one is directed ag ainst the cytotoxic T-lymphocyte-associated antigen 4 (CT LA4; CT LA-4), with potential immune checkpoint inhibitory and antineoplastic activities. Upon administration, antiPD1/anti-CT LA4 antibody mixture PSB205 targets and binds to both PD-1 and CT LA4 expressed on tumor-infiltrating lymphocytes (TILS) and inhibits the PD-1- and CT LA4mediated downregulation of T-cell activation and proliferation. This restores immune function and activates a cytotoxic T-lymphocyte (CTL)-mediated immune response ag ainst tumor cells. Both PD-1 and CT LA4 are selectively expressed on TILs in the tumor microenvironment (TME) and neg atively regulate the activation and effector functions of T-cells. They play key roles in the downregulation of the immune system and tumor evasion from host immunity. Dual checkpoint blockade of PD1 and CT LA4 enhances Tcell activation and proliferation more than the blockade of either immune checkpoint receptor alone. 